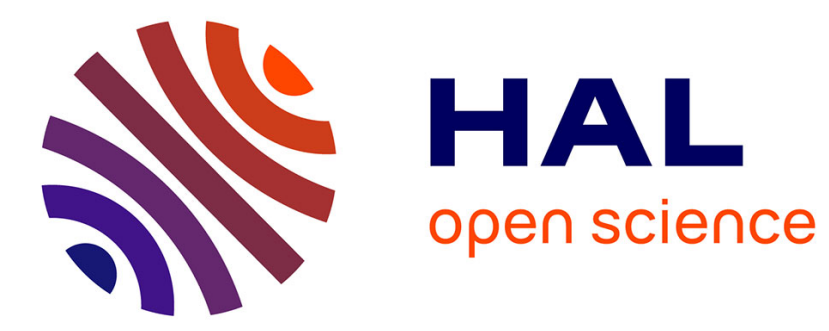

\title{
Scaling laws for the laser welding process in keyhole mode
}

\author{
Rémy Fabbro
}

\section{To cite this version:}

Rémy Fabbro. Scaling laws for the laser welding process in keyhole mode. Journal of Materials Processing Technology, 2019, 264, pp.346-351. 10.1016/j.jmatprotec.2018.09.027 . hal-02063550

\section{HAL Id: hal-02063550 https://hal.science/hal-02063550}

Submitted on 11 Mar 2019

HAL is a multi-disciplinary open access archive for the deposit and dissemination of scientific research documents, whether they are published or not. The documents may come from teaching and research institutions in France or abroad, or from public or private research centers.
L'archive ouverte pluridisciplinaire HAL, est destinée au dépôt et à la diffusion de documents scientifiques de niveau recherche, publiés ou non, émanant des établissements d'enseignement et de recherche français ou étrangers, des laboratoires publics ou privés. 


\title{
Scaling laws for the laser welding process in keyhole mode
}

\author{
Remy Fabbro \\ PIMM Laboratory (ENSAM-CNRS-CNAM), 151 Boulevard de l'Hôptal, 75013, Paris, France
}

\section{A R T I C L E I N F O}

Associate editor C.H. Caceres

Keywords:

Keyhole mode laser welding

Keyhole depth

Scaling law

Selective laser melting

Additive manufacturing

\begin{abstract}
A B S T R A C T
This study shows that the keyhole model derived for determining the scaling laws of keyhole depths for laser welding when high power incident laser beams are used (typically in the multi-kW incident power range), can be also applied to determine the melted depths observed during the Selective Laser Melting process, where much lower incident powers of typically few hundred watts are focused on very small focal spots. The solution of the thermal analysis of this keyhole configuration is described by only three independent dimensionless parameters that are also involved for the analysis of a more general problem of heat conduction using similar input parameters. This global approach and the keyhole model describing the process of laser welding have been also validated by analyzing the melted depths generated by the Selective Laser Melting process. The dependence of the melted depths on the operating parameters of this process has been established, as well as the formation thresholds of the keyhole.
\end{abstract}

\section{Introduction}

Laser welding, which has been used since the 1970s, has become one of the most important laser processes in the industrial world. It allows the assembly of metal parts for a very wide range of thicknesses, from very thick, greater than ten millimeters, thanks to the use of power lasers delivering powers in the multi-kW range, to much smaller thicknesses, less than a millimeter using lasers of much lower power. Many experimental, analytical or numerical studies have made it possible to understand the main physical processes occurring during this very characteristic and complex welding mode, the keyhole $(\mathrm{KH})$ welding, whose melt pool transverse cross sections are characterized by rather large aspect ratios $\mathrm{R}$, defined as the melt pool depth/laser spot diameter (Katayama, 2013). The prediction or the analysis of these $\mathrm{KH}$ depths according to the different operating parameters and materials used is therefore of the utmost importance for this application.

In addition, metal addition manufacturing processes, and more particularly the Selective Laser Melting (SLM) of powders, have also become more recently widely used processes (Yap et al., 2015). They produce molten zones of much smaller dimensions, but which can also present the same characteristics of the keyhole mode observed in welding (so with high aspect ratio), whereas the operating parameters used are very different (typically laser incident powers of a few hundred $\mathrm{W}$, laser spot diameters less than $0.1 \mathrm{~mm}$ and processing speeds of the order of $\mathrm{m} / \mathrm{s}$ ). Therefore, the occurrence of the $\mathrm{KH}$ mode for SLM conditions has been suggested, but never really proven quantitatively, and the knowledge of these melted depths is also very important because the quality of the resulting densification has been shown to be directly related to the melt pool sizes (Tang et al., 2017).

It is the purpose of this article to show that these two very different processes can both be described quantitatively by the same model describing the evolution of the aspect ratio $\mathrm{R}$ according to the operating parameters used and the thermo-physical parameters of the material. In a first step, the use of Buckingham's theorem allows to define the number of independent parameters controlling this thermal problem and justifies its solution thus determined, which is recalled. This model is then applied to the analysis of recently published experimental data obtained in SLM conditions, and it is shown that it is possible to reproduce precisely these experimental data as well as the observed thresholds for $\mathrm{KH}$ formation.

\section{Scaling law methodology}

\subsection{Definition of the problem}

In order to determine the scaling laws that control the $\mathrm{KH}$ depth e as a function of the main operating parameters and thermophysical properties of the welded material, several simplifying hypothesis have been used. The $\mathrm{KH}$ is assumed to be a vertical cylinder with a diameter $\mathrm{d}$ that is equal to the spot diameter of the incident laser beam; this $\mathrm{KH}$ is moving with the welding speed $\mathrm{V}$, inside a material at an initial temperature $\mathrm{T}_{0}$. The incident laser beam is $\mathrm{P}$ and $\mathrm{A}$ is the fraction of this power absorbed inside the $\mathrm{KH}$. One knows also that the $\mathrm{KH}$ walls must have a temperature at least equal to the vaporization temperature $\mathrm{T}_{\mathrm{v}}$; 
So, one will consider that the wall temperature of the cylindrical $\mathrm{KH}$ is constant at $\mathrm{T}_{\mathrm{v}}$. The used material is also characterized by its heat conductivity $K(\mathrm{~W} / \mathrm{m} . \mathrm{K})$ and by one of the two last thermophysical parameters: its heat capacity per unit volume $\rho C_{p}\left(J / m^{3} . K\right)$ or its diffusivity $\kappa\left(\mathrm{m}^{2} / \mathrm{s}\right)$.

So, in the frame of these hypothesis, one can consider that this problem is totally defined and closed by these previous $\mathrm{p}=7$ parameters: the resulting $\mathrm{KH}$ depth $\mathrm{e}(\mathrm{m})$, function of the 3 operating parameters, which are $\mathrm{P}(\mathrm{W}), \mathrm{V}(\mathrm{m} / \mathrm{s}), \mathrm{d}(\mathrm{m})$, the 3 thermophysical parameters: $K(\mathrm{~W} / \mathrm{m} . \mathrm{K}), \rho \mathrm{Cp}\left(\mathrm{T} / \mathrm{m}^{3} \cdot \mathrm{K}\right)$ and the $\mathrm{KH}$ wall temperature relative to the initial material temperature $\left(\mathrm{T}_{\mathrm{v}}-\mathrm{T}_{0}\right)(\mathrm{K})$. This means that there is a unique relation involving these $\mathrm{p}=7$ parameters.

Moreover, these 7 parameters are only depending of $\mathrm{u}=4$ fundamental units, which are the mass $[\mathrm{M}]$, the length $[\mathrm{L}]$, the time $[\mathrm{T}]$ and the temperature $[\mathrm{K}]$. Therefore, the Vaschy-Buckingham $\pi$-theorem (Buckingham, 1914) states that under these conditions, there must exist $\mathrm{p}-\mathrm{u}=3$ dimensionless independent parameters $\left(\pi_{1}, \pi_{2}\right.$ and $\left.\pi_{3}\right)$, derived from these initial p parameters, which must satisfy a relation $\mathrm{f}\left(\pi_{1}\right.$, $\left.\pi_{2}, \pi_{3}\right)=0$.

\subsection{Construction of the 3 dimensionless independent parameters}

From these 7 initial parameters, 3 dimensionless independent parameters have to be defined (a given dimensionless parameter cannot be derived from another one). There are several possibilities for this construction, by choosing ratios of parameters (or combination of parameters) using for example units of length, velocities, power, power per unit length or volume. A first obvious dimensionless parameter $\pi_{1}$ is the ratio e/d, which is none other than the usually defined aspect ratio $\mathrm{R}$ of the $\mathrm{KH}$. A second dimensionless parameter can be defined as $\pi_{2}=$ $\mathrm{V} \rho \mathrm{C}_{\mathrm{p}} \mathrm{d} / K$, which the ratio of the welding speed $\mathrm{V}$ and another velocity such as $K /\left(\rho \mathrm{C}_{\mathrm{p}} \mathrm{d}\right)$. In fact one can recognize that this parameter is si-

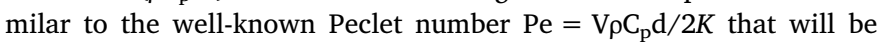
used below instead. A third dimensionless parameter can be $\pi_{3}=\mathrm{P}_{\mathrm{a}}$ / $\left(\mathrm{d} K\left(\mathrm{~T}_{\mathrm{v}}-\mathrm{T}_{0}\right)\right.$, which is the ratio of two powers, one is the absorbed laser power $\mathrm{P}_{\mathrm{a}}=\mathrm{A} \mathrm{P}$ (with $\mathrm{A}$ and $\mathrm{P}$ being the absorptivity and the incident power respectively), and the other one results from the combination: d.K. $\left(\mathrm{T}_{\mathrm{v}}-\mathrm{T}_{0}\right)$.

So the Vashy-Buckingham $\pi$-theorem says that it exists one relation between these 3 dimensionless parameters, which could be written as: $\pi_{1}=\mathrm{R}=\mathrm{F}\left(\pi_{3}, \pi_{2}\right)$.

Now, if one adds that the experimentally observed KH depths are usually proportional to the laser power $\mathrm{P}$, one could finally write:

$\pi 1=R=\frac{e}{d}=\pi 3 \cdot f(P e)=\frac{P_{a}}{d . K .\left(T_{v}-T_{0}\right)} \cdot f(P e)$

The relation (1) has been obtained only from dimensional analysis, which is rather efficient because it already gives an interesting scaling law with the parameters of this thermal problem. However, a complete dependence with all the involved parameters is not obtained, because the function $\mathrm{f}(\mathrm{Pe})$ is not defined here. We will see in Section 3 how $\mathrm{f}(\mathrm{Pe})$ can be only obtained from a complete solution of this thermal problem.

\subsection{Other possibilities for defining dimensionless parameters}

In the previous analysis, the dimensionless parameter $\pi_{1}=\mathrm{e} / \mathrm{d}=\mathrm{R}$ is adapted to the process of laser welding in $\mathrm{KH}$ mode, because it involves deep penetrations characterized by large $\mathrm{KH}$ depths e compared to $\mathrm{KH}$ diameters $\mathrm{d}$ (i.e. $\mathrm{R}>1$ ). But for laser processes involving heat diffusion, (as surface treatments such as laser hardening or surface melting), where the thickness of the affected material has to be determined, a characteristic normalizing dimension that would be more appropriate to this process of heat diffusion, could be some diffusion length $\delta$ obtained during the time $\tau: \delta=(\kappa . \tau)^{1 / 2}$, where $\kappa=K /\left(\rho \mathrm{C}_{\mathrm{p}}\right)$ is the heat diffusivity and $\tau=\mathrm{d} / 2 \mathrm{~V}$ is a characteristic dwell time. So another dimensionless parameter can then be defined such as: $\pi_{1}{ }^{\prime}=\mathrm{e} /$ $\delta$. One can easily see that $\pi_{1}$ and $\pi_{1}$ ' are related through the relation:

$\pi_{1}^{\prime}=\pi_{1} \cdot 2 \mathrm{Pe}^{1 / 2}$ or $\mathrm{e} / \delta=2 \mathrm{R} \cdot \mathrm{Pe}^{1 / 2}$

One could also consider another dimensionless parameter $\pi_{3}{ }^{\prime}=\Delta \mathrm{H} /$ $\Delta \mathrm{h}(\mathrm{T})$, which is the ratio of two energy densities, being expressed in $\mathrm{J} /$ $\mathrm{m}^{3}$. This approach was initially used by Hann et al. (2011) for describing the melted depths evolution during laser processing. King et al. (2014) showed that the energy density $\Delta H$ represents the energy absorbed A.P. $\tau$ during the dwell time $\tau$, which is distributed inside a volume defined by the focal spot diameter and the diffusion length $\delta: \pi(d /$ $2)^{2} \delta$.

This energy density is finally written as $\Delta \mathrm{H}=\left(2^{3 / 2} \pi\right)^{1 / 2}$.4.AP. $\tau /$ $\left(\pi \cdot \mathrm{d}^{2} . \delta\right)=2^{3 / 4} \mathrm{AP} /\left(\pi \kappa \mathrm{V}(\mathrm{d} / 2)^{3}\right)^{1 / 2}$ (Rubenchick et al., 2018). (The term $\left(2^{3 / 2} \pi\right)^{1 / 2}$ was introduced so that $\Delta \mathrm{H}$ is consistent with the initial definition of Hann et al. (2011)

The second energy density $\Delta h(T)$ can be defined by using the usual enthalpy formulation $\Delta \mathrm{h}(\mathrm{T})=\rho \mathrm{C}_{\mathrm{p}}$. $\left(\mathrm{T}-\mathrm{T}_{0}\right)$. If the laser welding process in the $\mathrm{KH}$ mode is analyzed, the enthalpy at vaporization $\Delta \mathrm{h}\left(\mathrm{T}_{\mathrm{v}}\right)$ should be used. But one could also use the enthalpy at the melting $\Delta h\left(T_{m}\right)$, if the melting temperature $\mathrm{T}_{\mathrm{m}}$ is the main involved characteristic temperature, as for example in surface treatment.

Similarly to Eq. (2), one has the following relation between $\pi_{3}$ ' and $\pi_{3}$ :

$\pi_{3}^{\prime}=\frac{\Delta H}{\Delta h\left(T_{v}\right)}=\left(\frac{2^{7 / 2}}{\pi \cdot P e}\right)^{1 / 2} \cdot \pi_{3}$

Finally, it is also possible to define another energy density $\Delta \mathrm{H}_{\mathrm{O}}$ (in $\mathrm{J} / \mathrm{m}^{3}$ ) that is only related to the operating parameters $\mathrm{P}, \mathrm{V}, \mathrm{d}$ such as: $\Delta \mathrm{H}_{\mathrm{O}}=\mathrm{AP} /\left(\mathrm{V} . \mathrm{d}^{2}\right)$. Similarly to Eq. (3), a dimensionless parameter $\pi_{3}$ " $=\Delta \mathrm{H}_{\mathrm{O}} / \Delta \mathrm{h}\left(\mathrm{T}_{\mathrm{v}}\right)$ could be defined. These different dimensionless parameters verify the relation:

$\pi_{3}^{\prime \prime}=\frac{1}{2 P e} \cdot \pi_{3}=\left(\frac{\pi}{2^{11 / 2} \cdot P e}\right)^{1 / 2} \cdot \pi_{3}^{\prime}$

The different dimensionless parameters involved in this paper are summarized in Table 1:

\section{Solution of this thermal model}

\subsection{Analysis of high power laser experiments}

With the different hypothesis for the KH thermal model defined in $\S$ 2.1 , it is possible to determine the $\mathrm{KH}$ depth resulting from these conditions and compare it with the previous scaling law of Eq. (1). As this determination has already been detailed in a previous publication (Fabbro et al., 2017), the main results will be shortly recalled here.

One considers that the absorbed laser power $\mathrm{P}_{\mathrm{a}}$ is homogenously distributed over the $\mathrm{KH}$ wall surface at $\mathrm{T}_{\mathrm{v}}$, along the $\mathrm{KH}$ depth e. Therefore, if one knows the absorbed power per unit depth $\mathrm{P}_{\mathrm{z}}=\mathrm{dP} / \mathrm{dz}$ that is conducted through the $\mathrm{KH}$ wall necessary for maintaining the $\mathrm{KH}$ surface at $T_{v}$, the KH depth must simply verify the relation $e=P_{a} / P_{z}$.

For determining the absorbed power per unit depth $\mathrm{P}_{\mathrm{z}}=\mathrm{dP} / \mathrm{dz}$, we assume a 2D thermal field induced inside the material, because the $\mathrm{KH}$ aspect ratio $R \geq 1$. Considering stationary conditions, it can be shown that the solution of the $2 \mathrm{D}$ heat equation is then only dependent of the

Table 1

Possible dimensionless parameters involved in this thermal problem that depends of the 7 parameters : $\mathrm{e}(\mathrm{m}), \mathrm{P}(\mathrm{W}), \mathrm{V}(\mathrm{m} / \mathrm{s}), \mathrm{d}(\mathrm{m}), K(\mathrm{~W} / \mathrm{m} \mathrm{K}), \rho \mathrm{Cp}\left(\mathrm{J} / \mathrm{m}^{3} \mathrm{~K}\right)$, $\left(\mathrm{T}_{\mathrm{v}}-\mathrm{T}_{0}\right)(\mathrm{K})$. The relations between them are given by the Eqs. (2)-(4).

\begin{tabular}{llllll}
$\begin{array}{l}\pi_{1}(=\mathrm{R}) \\
\text { (aspect ratio) }\end{array}$ & $\begin{array}{l}\pi_{2}(=\mathrm{Pe}) \\
(\text { Pe number })\end{array}$ & $\pi_{3}$ & $\pi_{1}^{\prime}$ & $\pi_{3}^{\prime}$ & $\pi^{\prime \prime}{ }_{3}$ \\
\hline $\mathrm{e} / \mathrm{d}$ & ${\mathrm{V} \rho \mathrm{C}_{\mathrm{p}} \mathrm{d} / 2 K}$ & $\begin{array}{l}\mathrm{AP} /\left(\mathrm{d} K\left(\mathrm{~T}_{\mathrm{v}^{-}}\right.\right. \\
\left.\mathrm{T}_{0}\right)\end{array}$ & $\mathrm{e} / \delta$ & $\begin{array}{l}\Delta \mathrm{H} / \Delta \mathrm{h} \\
\left(\mathrm{T}_{\mathrm{v}}\right)\end{array}$ & $\begin{array}{l}\left(\mathrm{AP}^{\prime} / \mathrm{Vd}^{2}\right) / \Delta \mathrm{h} \\
\left(\mathrm{T}_{\mathrm{v}}\right)\end{array}$
\end{tabular}


Pe number, the KH diameter $d$ and the two temperatures $T_{v}$ and $T_{0}$. As the thermal field is now determined, the resulting heat flux per unit depth $\mathrm{P}_{\mathrm{z}}$ conducted through the $\mathrm{KH}$ wall can be computed and is then given by:

$P z=K \cdot\left(T_{v}-T_{0}\right) \cdot g(P e)$

In Eq. (5), $\mathrm{g}(\mathrm{Pe})$ is a function numerically determined of the $\mathrm{Pe}$ number. As a result, the aspect ratio $\mathrm{R}$ of the $\mathrm{KH}$ is then given by:

$R=\frac{e}{d}=\frac{P_{a}}{d \cdot P_{z}}=\frac{P_{a}}{d \cdot K \cdot\left(T_{v}-T_{0}\right) \cdot g(P e)}$

By using the independent dimensionless parameters defined in Section 2.3, one can see that the relation (6) can be rewritten as $\pi_{1}=$ $\pi_{3} / \mathrm{g}(\mathrm{Pe})$, which is similar to the relation (1); but now the function $\mathrm{g}(\mathrm{Pe})$ is determined.

Remark: The absorbed power $\mathrm{P}_{\mathrm{a}}$ is related to the incident one $\mathrm{P}$ by the relation $\mathrm{P}_{\mathrm{a}}=$ A.P, where $\mathrm{A}$ is the fraction of incident power trapped inside the KH. Due to the cylindrical shape of the $\mathrm{KH}$, the laser beam is absorbed by multi-reflections inside it. The Gouffe (1945) formula takes into account this process and shows that the resulting absorptivity $\mathrm{A}$ depends of the aspect ratio $\mathrm{R}$ and varies from $\mathrm{A}_{0}$ for small aspect ratio (typically $\mathrm{A}_{0} \approx 0.45$, for a metallic surface, with a $1.06 \mu \mathrm{m}$ wavelength laser) to about 0.8-0.9 for KH's with large aspect ratio $\mathrm{R}$ (typically for $\mathrm{R}$ $\geq 7-8$ ). For the analysis of macro-experiments (shown in Fig. 1), where $\mathrm{R}$ is large, we will therefore consider that $\mathrm{A} \approx 1$; but for SLM microexperiments, as $\mathrm{R}$ is not so important, one should rather consider that $\mathrm{A}$ $\approx \mathrm{A}_{0}$.

In order to easily use Eq. (6), we have also shown the great interest in considering that within a given Peclet range, $g(\mathrm{Pe})$ can be assumed to be a linear function of Pe such as: $g(P e)=m \cdot P e+n$. The constants $m$ and $\mathrm{n}$ are only depending of the considered Pe range (for example, typically $\mathrm{m} \approx 2.5$ and $\mathrm{n} \approx 3$ for $0.3<\mathrm{Pe}<10$, which corresponds to the main usual processing conditions for steel alloys, both for laser $\mathrm{KH}$ welding or SLM process conditions; for lower Pe, it is observed that $\mathrm{m}$ increases and $n$ decreases).

Therefore using this linear relation for $\mathrm{g}(\mathrm{Pe})$, Eq. (6) can be rewritten as:

$R=\frac{R_{0}}{\left(1+\frac{V}{V_{0}}\right)}$

where $R_{0}=\frac{A \cdot P}{n \cdot d \cdot K \cdot\left(T_{v}-T_{0}\right)}$ and $V_{0}=2 \frac{n}{m} \frac{K}{d \rho C_{p}}$

Eqs. (7a) and (7b) give the variation of the aspect ratio $R$ as a function of the operating parameters and the thermophysical properties of the material. One can first remark that Eq. 7-a shows a linear

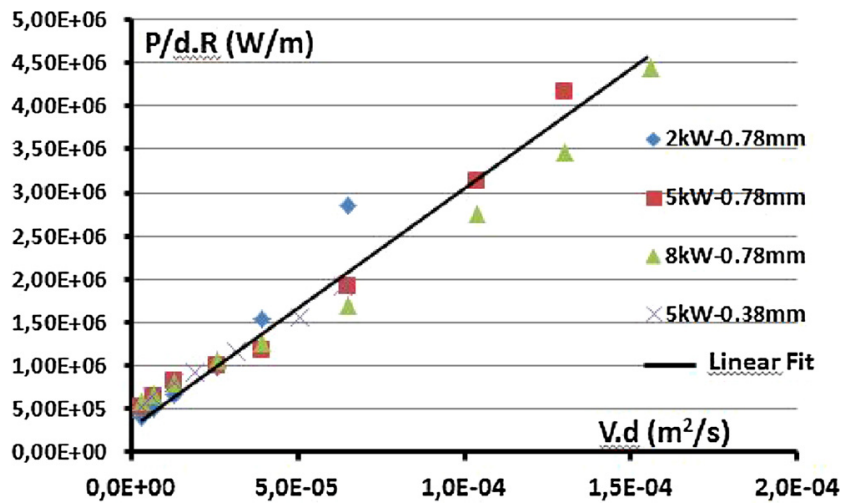

Fig. 1. For St35 steel and different operating parameters (incident powers and focal spot diameters), plot of $\mathrm{P} /(\mathrm{d} . \mathrm{R})$ as a function of the parameter V.d and corresponding best linear fit (KH depths obtained by Suder and Williams, (2014) at $1.06 \mu \mathrm{m}$ laser wavelength). dependence of $1 / \mathrm{R}$ with the welding speed $\mathrm{V}$; so this behavior should be easily verified for experimental data.

In addition to these previous results, Eq. (7a) can also be rewritten in a more interesting general form, which can be applied with any operating parameters $\mathrm{P}, \mathrm{V}$ and $\mathrm{d}$ and which separates the role of the operating parameters and the thermophysical one:

A.P $/($ d.R $)=a+$ b.(V.d)

where

$\mathrm{a}=\mathrm{n} \cdot K \cdot\left(\mathrm{T}_{\mathrm{v}}-\mathrm{T}_{0}\right)=\mathrm{n} \cdot(\mathrm{P} / \mathrm{d})_{0}$,

$(\mathrm{P} / \mathrm{d})_{0}=K \cdot\left(\mathrm{T}_{\mathrm{v}}-\mathrm{T}_{0}\right)$ is a characteristic power per unit length necessary for a $\mathrm{KH}$, with the used material,and

$\mathrm{b}=\mathrm{m} \cdot\left(\rho \mathrm{C}_{\mathrm{p}}\right) \cdot\left(\mathrm{T}_{\mathrm{v}}-\mathrm{T}_{0}\right) / 2=\mathrm{m} \cdot \Delta \mathrm{h}\left(\mathrm{T}_{\mathrm{v}}\right) / 2$

So for a given material, Eq. (8) shows that for any aspect ratio $\mathrm{R}$ resulting of the use of different operating parameters $P, V$ and $d$, the plot of the variable $\mathrm{P} /(\mathrm{d} . \mathrm{R})$ as a function of $(\mathrm{Vd})$ is a linear function whose ordinate at origin $\mathrm{a}$ and slope $\mathrm{b}$ are only depending of the thermophysical properties of the material and the range of the Peclet number (through the $\mathrm{m}$ and $\mathrm{n}$ dependence). When the range of the welding speed $\mathrm{V}$ (or the corresponding Pe number) decreases, as $\mathrm{m}$ increases and $n$ decreases, one can see that the ordinate at the origin a decreases and the slope $\mathrm{b}$ of the linear function increases.

In Eq. (8), as previously discussed, one can admit that $\mathrm{A} \approx 1$, because large aspect ratios are considered here.

This behavior has been verified by analyzing the published data by Suder and Williams (2014) on KH depths obtained on St35 steel at 1.06 $\mu \mathrm{m}$ laser wavelength, for different incident laser powers and focal spots. On Fig. 1, the variable $y=P /(d . R)$ has been plotted as a function of $x=$ (V.d) for these different operating parameters. One sees that the data can be fitted by a unique linear function, $y=a_{1}+b_{1}$. x, with $a_{1} \approx 3.0$ $10^{5} \mathrm{~W} / \mathrm{m}$ and $\mathrm{b}_{1} \approx 2.610^{10} \mathrm{~J} / \mathrm{m}^{3}$. By considering that $\mathrm{T}_{\mathrm{v}} \approx 3100 \mathrm{~K}, \mathrm{~T}_{\mathrm{m}}$ $\approx 1800 \mathrm{~K}, \mathrm{~m} \approx 2.5$ and $\mathrm{n} \approx 3$ and using Eq. 9 , one finds a mean value of $K \approx 40 \mathrm{~W} / \mathrm{m} . \mathrm{K}$ and $\mathrm{C}_{\mathrm{p}} \approx 950 \mathrm{~J} / \mathrm{m}^{3} . \mathrm{K}$, which appears to be rather close to what is expected for this kind of steel (Mills, 2002).

From Fig. 1 it can be seen that the differences between the experimental data and the representative line of the model using realistic thermodynamic parameters are quite small, which can be roughly estimated at about $20 \%$ for the large aspect ratios $\mathrm{R}$. This discrepancy seems to increase with the welding speed (or when the aspect ratio $\mathrm{R}$ decreases).

One can therefore see that the scaling of the KH depths given by Eq. (7a) (7b)) (or (8)) is verified for these conditions of laser welding at high power and deep KH's. It has also been verified for $\mathrm{Cu}$ laser welding (Fabbro et al., 2017), and also for many other data obtained for different operating conditions.

\subsection{Analysis of $\mathrm{KH}$ mode during selective laser melting additive process}

Selective Laser melting (SLM) process uses rather low laser powers (typically several hundred watts) and focused laser beams (typically around $100 \mu \mathrm{m}$ ). It is believed that the depth of the molten pool is controlled by heat conduction in the powder bed and the underlying base material. One also observes for high laser powers (or low scanning speeds) a change in the cross section shape of the molten pool: its melted depth becomes greater than the focal spot diameter, which is characteristic of the $\mathrm{KH}$ mode.

This transition from conduction to a $\mathrm{KH}$ mode occurs above a threshold that has been analyzed by King et al. (2014). By plotting the melted depth normalized by the beam radius (which is twice the aspect ratio parameter $\mathrm{R}$ defined here) as a function of a normalized enthalpy $\mathrm{X}=\Delta \mathrm{H} / \mathrm{h}_{\mathrm{s}}$, they observed a first transition threshold characterizing the melt pool formation for $\mathrm{X}_{\mathrm{m}}=\Delta \mathrm{H} / \mathrm{h}_{\mathrm{s}} \approx 10$; Then, for higher normalized enthalpies, the KH mode appeared typically for a threshold $\mathrm{X}_{\mathrm{v}}=\Delta \mathrm{H} / \mathrm{h}_{\mathrm{s}}$ 
$\approx 25-30$. For defining their normalized enthalpy $\Delta H / h_{s}$, they used the non-dimensional analysis of Hann et al. (2011) where $h_{s}=\rho C_{p} T_{m}\left(h_{s}\right.$ is similar to a "melting enthalpy" but rigorously, it differs from the usual $h$ $\left(\mathrm{T}_{\mathrm{m}}\right)$ melting enthalpy, defined in Section 2.3, because the reference to the initial temperature $T_{0}$ of the material is missing; this remark is important if one considers that the initial temperature $\mathrm{T}_{0}$ may change due to some possible preheating occurrence during the manufacturing process).

Rubenchick et al. (2018) have also reported a more recent analysis of the evolution of these melted depths e as a function of operating parameters for several experiments on steel, Inconel 625 and Ti-6Al-4 V alloys, realized on different machines. They plotted a different normalized depth $(\mathrm{e} / \delta)$, as a function of the same normalized enthalpy $\Delta \mathrm{H} /$ $\mathrm{h}_{\mathrm{s}}$, and they showed that all these data could be collapsed in one curve. This result is interesting because it shows that there is a unique mechanism underlying these data obtained for very different machines, operating parameters and materials. As different parameters of particle diameters and layer thicknesses were used, this means that these parameters are not relevant for controlling the melted depths evolution. This can be explained by the fact that the thickness of the powder bed typically used in SLM experiments is about 100 microns (corresponding to 2-3 particle diameters); therefore with a typical density of the powder of about $40-50 \%$ of the solid density, this should give a thickness of liquid (or solid) layer of about $40-50$ microns, which is rather small compared to the melted depths of about several hundred of microns observed during this process. For the following discussion in Section 3.3, these different normalized data have been reproduced in Fig. 2.

For the analysis of these results, Rubenchick et al. (2018) used a thermal model of the melt pool formation, only based on a conductive process, where the laser beam is absorbed on the planar surface of the sample. With these hypothesis, they showed that the computed melted depth (normalized by $\delta$ ) is a function of two dimensionless parameters, the previous normalized enthalpy $\Delta \mathrm{H} / \mathrm{h}_{\mathrm{s}}$, and the inverse of the Peclet number Pe. Of course, this is in agreement with our analysis described in §2, which states that the (normalized) melted depth of this thermal problem only depends of 2 dimensionless parameters. Therefore, the fact that the data shown in Fig. 2 can be collapsed in one curve is rather

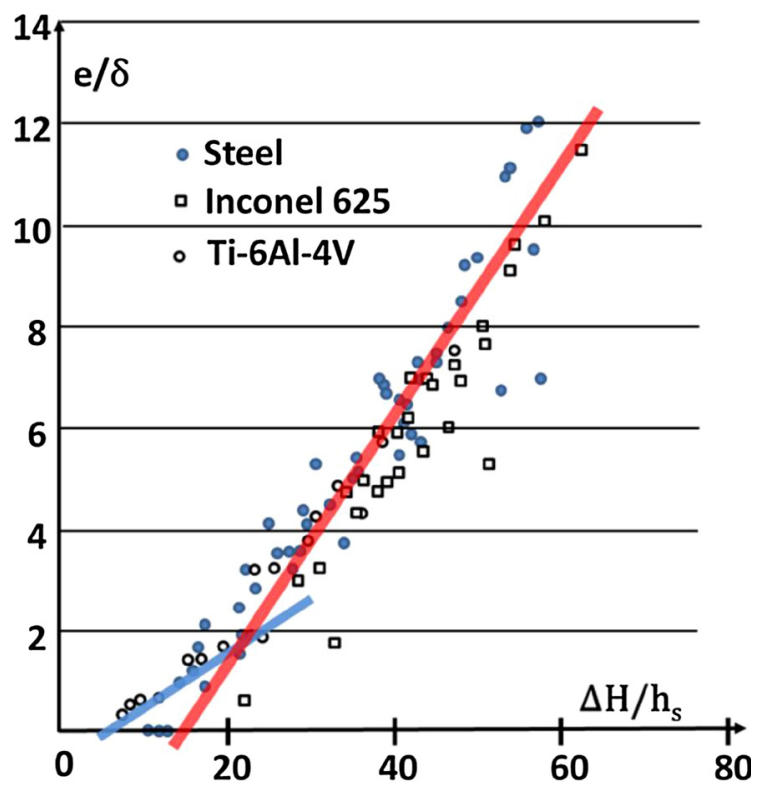

Fig. 2. Normalized melt pool depth $\mathrm{e} / \delta$ as a function of normalized enthalpy $\Delta \mathrm{H} / \mathrm{h}_{\mathrm{s}}$ (from Rubenchick et al., 2018 and King et al., 2014). The data for the conduction regime have been fitted with the blue line and those for the $\mathrm{KH}$ regime with the red one (For interpretation of the references to colour in this figure legend, the reader is referred to the web version of this article). surprising because it shows a relation between only 2 parameters (the normalized depths and enthalpies), and the dependence with the Peclet number does not seem to appear here. The reason of this behavior will be explained in Section 3.3.

Moreover, the use of their thermal model leads to another inconsistency reported by these authors: for high density experiments, leading to observed high aspect ratios characteristic of $\mathrm{KH}$ geometries, their simulations show that the peak surface temperature is much greater than $T_{v}$. For these conditions, it is clear that a pure conductive model is no more relevant for describing the resulting melt pool shape, because for these high temperatures, the resulting induced recoil pressure strongly deforms the melt pool surface and leads to the usual elongated $\mathrm{KH}$ geometry.

However, our approach described in $\S 2$ explains the reason for this similarity between the scaling laws derived from a pure conductive model with a planar melt pool surface, and those derived from a cylindrical $\mathrm{KH}$ model (and also those derived from experiments, as we will show in the next section). These are the same three independent dimensionless parameters, or others related to them, which can be used for the different solutions describing the thermal field of these two geometries. As discussed in $\S 2$, the use of other dimensionless parameters is possible because they are derived from the first three one by relations involving the Pe number.

We will see in the next Section 3.3 how the results described by the Fig. 2, can be reproduced by using a description of a cylindrical $\mathrm{KH}$ model that is moving at high velocity.

\subsection{Discussion of the results presented in Fig. 2}

Fig. 2 shows that for SLM processing conditions, the normalized melted depths $\mathrm{Y}=\mathrm{e} / \delta$ for 3 different alloys, appear to be a function of the normalized enthalpies $\mathrm{X}=\Delta \mathrm{H} / \mathrm{h}_{\mathrm{s}}$ that can be roughly collapsed in one linear curve.

Following the analysis of King et al. (2014), the conduction mode appears for $\mathrm{X}>10$ and the KH mode for $\mathrm{X} \geq 25-30$. One can see that it is then possible to fit these experimental points of these two regimes by a linear scaling of the form:

$\mathrm{Y}=\mathrm{Y}_{0}+\alpha\left(\mathrm{X}-\mathrm{X}_{0}\right)$

which have been drawn on Fig. 2 .

For the conduction mode, $\mathrm{Y}_{0} \approx 0$ and $\mathrm{X}_{0}=\mathrm{X}_{\mathrm{m}} \approx 10$ (this value of the threshold $X_{\mathrm{m}}$ can be more easily determined by using the original results of King et al. (2014). Similarly, for the KH mode, using Fig. 2, it is found that $Y_{0} \approx 2$ and $X_{0}=X_{v} \approx 25-30$ and also the slope of this linear fit is $\alpha_{\mathrm{v}} \approx 0.25$.

In order to explain these results for the $\mathrm{KH}$ mode, we will consider that the melted shape for SLM conditions results from a KH formation whose depth is given by Eq. (7a). But, for usual SLM operating parameters, where typically $\mathrm{V} \approx 0.5-1 \mathrm{~m} / \mathrm{s}$, one can verify that $\mathrm{V}>>\mathrm{V}_{0}$ (with the heat diffusivity $\kappa \approx 510^{-6} \mathrm{~m}^{2} \mathrm{~s}^{-1}$, and $\mathrm{d} \approx 100 \mu \mathrm{m}$, typically $\mathrm{V}_{0} \approx 0.12 \mathrm{~m} / \mathrm{s}$ and $\mathrm{Pe} \geq 5$ ). Therefore, for these operating conditions, Eq. (7a) can be rewritten as:

$\mathrm{R}=\mathrm{R}_{0} \cdot \mathrm{V}_{0} / \mathrm{V}$

Now, if one expresses the two sides of Eq. (11), by introducing the dimensionless parameters $\mathrm{e} / \delta$ and $\Delta \mathrm{H} / \mathrm{h}_{\mathrm{s}}$ used by Rubenchick et al. (2018), one obtains after some manipulations:

$R=\frac{e}{d}=\frac{e}{\delta} \cdot(4 P e)^{-1 / 2}=\frac{Y}{2 \cdot P e^{1 / 2}}$

and:

$R=\frac{R_{0} V_{0}}{V}=\frac{2 \cdot T_{m}}{m \cdot\left(T_{v}-T_{0}\right)} \cdot\left(\frac{A \cdot P}{V \cdot d^{2}}\right) \cdot \frac{1}{h_{s}}=\frac{\pi^{1 / 2}}{2^{3 / 4}} \cdot \frac{1}{2 \cdot P e^{1 / 2}} \cdot \frac{T_{m}}{m \cdot\left(T_{v}-T_{0}\right)}$.

$\frac{\Delta H}{h_{s}}$ 
Combining Eqs. (12) and (13), one finally finds a linear relation between $\mathrm{Y}=\mathrm{e} / \delta$ and $\mathrm{X}=\Delta \mathrm{H} / \mathrm{h}_{\mathrm{s}}$, such that $\mathrm{Y}=\alpha^{\prime} \cdot\left(\Delta \mathrm{H} / \mathrm{h}_{\mathrm{s}}\right)=\alpha^{\prime} . \mathrm{X}$, where the slope $\alpha^{\prime}$ is given by:

$\alpha^{\prime}=\frac{\pi^{1 / 2}}{2^{3 / 4}} \cdot \frac{T_{m}}{m \cdot\left(T_{v}-T_{0}\right)}$

If one uses $\mathrm{m} \approx 2.5, \mathrm{~T}_{\mathrm{v}} \approx 3100 \mathrm{~K}, \mathrm{~T}_{\mathrm{m}} \approx 1800 \mathrm{~K}$ and $\mathrm{T}_{0} \approx 300 \mathrm{~K}$, one obtains $\alpha^{\prime} \approx 0.27$ from (14). This value appears to be very close to the experimental one derived from the linear fit of Fig. 2 , where $\alpha \approx 0.25$.

So, it appears that it is because the Peclet numbers of the corresponding experiments reported in Fig. 2 are large that these data can be collapsed in one curve given by Eq. (11). It also confirms that the melted depths obtained from SLM experiments collected in Fig. 2 for various operating conditions, can be described as resulting from a $\mathrm{KH}$ formation, with an adequate thermal field description that considers a $\mathrm{KH}$ geometry (This conclusion could already be formulated because of the large aspect ratios commonly observed experimentally of these cross-sections.). Moreover, it is an additional validation of this $\mathrm{KH}$ model describing rather small KH's (but nevertheless with rather large aspect ratios) which are obtained for these various SLM operating parameters. Generating a KH under these SLM conditions characterized by high travel speeds is of course possible if one considers that the local intensity of the incident beam is very high (it is typically more than one order of magnitude higher than conventional laser welding). The $\mathrm{KH}$ is kept open, with a diameter corresponding approximately to the diameter of the laser spot, only because the very high recoil pressure resulting from this high incident laser intensity balances the surface tension that is very high for these small laser spot diameters.

In addition, because of the high travel speeds during the SLM process and due to the high hydrodynamic velocities induced inside the melt pool, it is observed that the $\mathrm{KH}$ no longer remains circular, but is rather elongated in the travel direction (Gunenthiram et al., 2018). In this case it is necessary to compare the heat flux from an elongated $\mathrm{KH}$ (typically with an elliptical section) with that from a cylindrical $\mathrm{KH}$. This calculation was performed by Miyazaki and Giedt 1982 and they show that for an elliptical $\mathrm{KH}$ the normalized heat flux (always defined by $\mathrm{g}(\mathrm{Pe})$ ) is higher, due to the larger lateral surface area of the elongated $\mathrm{KH}$, and increases linearly with the parameter $(\gamma-1)(\gamma$ is the ratio of the major axis of the ellipse in the travel direction (which therefore increases with the welding speed) and the minor axis of the ellipse, which is about the diameter of the laser spot). Typically for $\gamma \approx 2$ the difference between the two configurations is $17 \%$. As the heat flow is greater with an elliptical $\mathrm{KH}$, the corresponding depth should be lower. However, another effect should reduce this increase. Indeed, the surface temperature of the elongated $\mathrm{KH}$ is not uniform at $\mathrm{T}_{\mathrm{v}}$ : it is observed that only the front edge of the elongated $\mathrm{KH}$ is irradiated by the laser and only this front edge, located under the laser beam, is therefore brought to the vaporization temperature $\mathrm{T}_{\mathrm{v}}$. The rear part of this elongated $\mathrm{KH}$, which is formed by the hydrodynamics of the metallic liquid bypassing the $\mathrm{KH}$ front, has a surface temperature that is closer to the melting temperature $\mathrm{T}_{\mathrm{m}}$ than $\mathrm{T}_{\mathrm{v}}$. Under these conditions of nonuniform $\mathrm{KH}$ wall surface temperature, it is likely that the heat fluxes from these two different KH geometries are comparable. This may explain why these experimental data can be reproduced using the model with a circular $\mathrm{KH}$.

One can also add that for SLM conditions because of the used high welding speeds, the transfer mode of energy inside the SLM sample is dominated by the convective losses compared to conductive losses.

Finally, Eq. (11) can be rewritten in a much more practical equation where the operating parameters are more evidenced. It is easy to see that:

$R=\frac{R_{0} V_{0}}{V}=\frac{\left(\frac{A . P}{V \cdot d^{2}}\right)}{0.5 m \rho C_{p}\left(T_{v}-T_{0}\right)}=\frac{\Delta H_{0}}{\Delta h\left(T_{v}\right)^{\prime}}$

Eq. 15 shows that the aspect ratio $\mathrm{R}$ is equal to the ratio of two energy densities: $\Delta \mathrm{H}_{0}=\mathrm{AP} / \mathrm{Vd}^{2}$ that only contains the operating parameters, and $\Delta \mathrm{h}\left(\mathrm{T}_{\mathrm{v}}\right)^{\prime}=0.5 \mathrm{~m} . \Delta \mathrm{h}\left(\mathrm{T}_{\mathrm{v}}\right) \approx 0.5 \mathrm{~m} . \rho \mathrm{C}_{\mathrm{p}}\left(\mathrm{T}_{\mathrm{v}}-\mathrm{T}_{0}\right)$ is similar to an enthalpy at evaporation temperature (slightly modified through the convective parameter $0.5 \mathrm{~m}$ ).

\subsection{Determination of the threshold $X_{v}$}

The threshold $\mathrm{X}_{\mathrm{v}} \approx 25-30$ for KH generation has been experimentally determined by King et al. (2014). We show here how these results can be derived by using the $\mathrm{KH}$ model.

A first usual approach for defining the threshold of $\mathrm{KH}$ formation is to determine the operating conditions that induce the evaporation temperature at the surface of the sample. When a laser beam is moving at the surface of a material, the resulting peak temperature $\mathrm{T}_{\max }$ at the surface is determined by the following relation (Hügel and Graf, 2014):

$\frac{A \cdot P}{d}=K \cdot\left(T_{\max }-T_{0}\right) \cdot p \cdot\left(\frac{P e}{2}+q\right)^{1 / 2}$

In (16), $\mathrm{p}=\pi / 8^{1 / 2}$ and $\mathrm{q}=4 / \pi$ for a Gaussian intensity distribution.

For SLM conditions, as the Peclet numbers Pe are rather large, the relation (16) can be rewritten as:

$\frac{A \cdot P}{V \cdot d^{2}}=\frac{\pi}{8} \cdot h_{s} \cdot \frac{1}{P e^{1 / 2}} \cdot \frac{\left(T_{v}-T_{0}\right)}{T_{m}}$

Using (13) and (17), the corresponding threshold $X_{\mathrm{v} 1}$ can then be estimated:

$X_{v 1}=\frac{\Delta H}{h_{s}}=\frac{2^{2} 2^{3 / 4}}{\pi^{1 / 2}} \cdot\left(\frac{A \cdot P}{V \cdot d^{2}}\right) \cdot \frac{P e^{1 / 2}}{h_{s}}=\frac{\pi^{1 / 2}}{2^{1 / 4}} \cdot \frac{\left(T_{v}-T_{0}\right)}{T_{m}}$

For $\mathrm{T}_{\mathrm{v}} \approx 3100 \mathrm{~K}, \mathrm{~T}_{\mathrm{m}} \approx 1800 \mathrm{~K}$ and $\mathrm{T}_{0}=300 \mathrm{~K}$, one finds $\mathrm{X}_{\mathrm{v} 1} \approx 2.3$, which is quite one order magnitude smaller than the threshold observed experimentally. This means that reaching the evaporation temperature at the surface of the sample, is not a sufficient condition for the $\mathrm{KH}$ generation.

One could also consider that a $\mathrm{KH}$ can be defined when its aspect ratio $\mathrm{R}$ is greater than one. Therefore, our previous result that gives the aspect ratio $\mathrm{R}$ as a function of the operating parameters (Eq. (11)) can be used for estimating another threshold $\mathrm{X}_{\mathrm{v} 2}$. From the condition $\mathrm{R}=\mathrm{R}_{0} \cdot \mathrm{V}_{0} / \mathrm{V}=1$, one obtains:

$\frac{A \cdot P}{V d^{2}}=\frac{m \cdot \rho \cdot C_{p}\left(T_{v}-T_{0}\right)}{2}$

The corresponding threshold $\mathrm{X}_{\mathrm{v} 2}$ is then given by:

$$
\begin{aligned}
X_{v 2} & =\frac{\Delta H}{h_{s}}=\frac{2^{2} 2^{3 / 4}}{\pi^{1 / 2}} \cdot\left(\frac{A \cdot P}{V \cdot d^{2}}\right) \cdot \frac{P e^{1 / 2}}{h_{s}}=\frac{2 \cdot 2^{\frac{3}{4}}}{\pi^{\frac{1}{2}}} \cdot m \cdot \rho C_{p} \cdot\left(T_{v}-T_{0}\right) \frac{P e^{\frac{1}{2}}}{h_{s}} \\
& =\frac{2^{\frac{7}{4}}}{\pi^{\frac{1}{2}}} m \frac{\left(T_{v}-T_{0}\right)}{T_{m}} P e^{\frac{1}{2}}
\end{aligned}
$$

So, also for $\mathrm{T}_{\mathrm{v}} \approx 3100 \mathrm{~K}, \mathrm{~T}_{\mathrm{m}} \approx 1800 \mathrm{~K}, \mathrm{~T}_{0}=300 \mathrm{~K}$ and $\mathrm{m} \approx 2.5$, on finds: $\mathrm{X}_{\mathrm{v} 2} \approx 7.3 \mathrm{Pe}^{1 / 2}$. As for SLM operating conditions we have seen that the Peclet number is rather large ( $\mathrm{Pe} \approx 5-10$ ), this would correspond to $X_{\mathrm{v} 2} \approx 16-23$. This range for $X_{\mathrm{v} 2}$ has a much better agreement than $\mathrm{X}_{\mathrm{v} 1}$ with the experimental determination.

Finally, a third threshold $\mathrm{X}_{\mathrm{v} 3}$ for $\mathrm{KH}$ generation can be defined by using an approach based on the analysis of the $\mathrm{KH}$ front geometry: for an efficient beam trapping, the $\mathrm{KH}$ front inclination must be such that the reflected beam on this front must be redirected downwards, towards the inside of the sample (Fabbro et al., 2017). This KH front inclination at threshold is therefore $45^{\circ}$ (this is also roughly equivalent of considering that $\mathrm{R} \approx 1$ ). The condition for obtaining an inclination angle of $45^{\circ}$ has already been estimated (Fabbro et al., 2017), and is given by the relation:

$\frac{A \cdot P}{V d^{2}}=\frac{\pi \cdot H_{0}}{4}$ 
where $\mathrm{H}_{0}$ is a modified melting enthalpy derived from the piston model (Semak and Matsunawa, 1997) that takes into account also some losses by heat diffusion. Using (21), the corresponding threshold $\mathrm{X}_{\mathrm{v} 3}$ is then:

$X_{v 3}=\frac{\Delta H}{h_{s}}=\frac{2^{2} 2^{3 / 4}}{\pi^{1 / 2}} \cdot\left(\frac{A \cdot P}{V \cdot d^{2}}\right) \cdot \frac{P e^{1 / 2}}{h_{s}}=2^{3 / 4} \pi^{1 / 2} \cdot \frac{H_{0}}{h_{s}} \cdot P e^{1 / 2}$

For the considered range of the Peclet number, it can be shown that $\mathrm{H}_{0} / \mathrm{h}_{\mathrm{s}} \approx 2$. So (22) gives:

$\mathrm{X}_{\mathrm{v} 3} \approx 6 . \mathrm{Pe}^{1 / 2} \approx 0.8 \mathrm{X}_{\mathrm{v} 2}$

For defining the KH formation threshold, Eq. (23) shows that the two very different approaches give similar results, which are quite close to the experimental threshold determination. It also means that reaching the evaporation temperature at the surface of the sample, defined by the threshold $X_{\mathrm{v} 1}$, is not a sufficient condition to generate a $\mathrm{KH}$ during these SLM operating conditions. The laser intensity should be increased in order to induce a significant depression of the melt pool.

\section{Conclusions}

In this study, using an approach based on energy conservation of the absorbed power inside a cylindrical $\mathrm{KH}$, an analytical model has been developed that gives the evolution of the KH depth as a function of the operating parameters and the thermophysical data of the used material. The main results can be summarized as follows:

- As a general law, it is obtained that the inverse of the KH depth appears to be a linear function of the welding speed. This point is always verified by corresponding experiments.

- The effects of all the operating parameters and thermophysical data of the used material have been clarified. The resulting $\mathrm{KH}$ depths obtained with multi-kW lasers can be predicted with a rather good agreement by this model, and it should be considered as an interesting tool in an industrial environment.

- It has also been shown that the melted depths observed during the Selective Laser machining process for different operating conditions and materials, can be reproduced using the same KH model. This implies that the involved SLM process can be quantitatively and definitively interpreted as a $\mathrm{KH}$ mode welding.

- This KH model defines the conditions for achieving the threshold for $\mathrm{KH}$ formation. It is shown that the occurrence of the evaporation temperature at the sample surface is not a sufficient condition for achieving this threshold.

\section{Declaration of interest}

None

\section{Acknowledgments}

I acknowledge fruitful discussions with Patrice Peyre, Morgan Dal and Matthieu Schneider. This work was performed under the auspices of the Centre National de la Recherche Scientifique (CNRS) at the PIMM laboratory.

\section{References}

Buckingham, E., 1914. On physically similar systems. Illustrations of the use of dimensional equations. Phys. Rev. 4 (4), 345-376.

Fabbro, R., Dal, M., Peyre, P., Coste, F., Schneider, M., Gunenthiram, V., 2017. Analysis and possible estimation of keyhole depths evolution, using laser operating parameters and material properties. LIA (Ed.), Proceedings of ICALEO 801-809.

Gouffe, A., 1945. Correction d'ouverture des corps noirs artificiels compte tenu des diffusions multiples internes. Revue d'Optique 24, 1-10.

Gunenthiram, V., Peyre, P., Schneider, M., Dal, M., Coste, F., Koutiri, I., Fabbro, R., 2018. Experimental analysis of spatter generation and melt-pool behavior during the powder bed laser beam melting process. J. Mater. Process. Technol. 251, 376-386.

Hann, D.B., Iammi, J., Folkes, J., 2011. A simple methodology for predicting laser-weld properties from material and laser parameters. J. Phys. D Appl. Phys. 44, 445401.

Hügel, H., Graf, T., 2014. Laser in der Fertigung, third ed. Springer, pp. 167 978-3-83481817-1.

Katayama, S., 2013. Introduction: fundamental of laser welding. In: Katayama, S. (Ed.), Handbook of Laser Welding Technologies. Woodhead Publishing Limited, Cambridge, UK, pp. 3-16.

King, W.E., Barth, H.D., Castillo, V.M., Gallegos, G.F., Gibbs, J.W., Hahn, D.E., Kamath, C., Rubenchik, A.M., 2014. Observation of keyhole-mode laser melting in laser powder-bed fusion additive manufacturing. J. Mater. Process. Technol. 214 2915-2925. https://doi.org/10.1016/j.jmatprotec.2014.06.005.

Mills, K.C., 2002. Recommended Values of Thermophysical Properties for Selected Commercial Alloys. Woodhead Publishing Limited, Abington Cambridge, UK.

Miyazaki, T., Giedt, W.H., 1982. Heat transfer from an elliptical cylinder moving through an infinite plate applied to electron beam welding. Int. J. Heat Mass Transf. - Theory Appl. 25 (6), 807-814.

Rubenchick, A.M., King, W.E., Wu, S.S., 2018. Scaling laws for additive manufacturing. J. Mater. Process. Technol. 257, 234-243.

Semak, V., Matsunawa, A., 1997. The role of recoil pressure in energy balance during laser materials processing. J. Phys. D Appl. Phys. 30 (18), 2541-2552. https://doi org/10.1088/0022-3727/30/18/008.

Suder, W.J., Williams, S., 2014. Power factor model for selection of welding parameters for CW laser welding. Opt. Laser Technol. 56, 223-229.

Tang, M., Pistorius, P.C., Beuth, J.L., 2017. Prediction of lack-of-fusion porosity for powder bed fusion. Addit. Manuf. 14, 39-48.

Yap, C.Y., Chua, C.K., Dong, Z.L., Liu, Z.H., Zhang, D.Q., Loh, L.E., Sing, S.L., 2015 Review of selective laser melting: materials and applications. Appl. Phys. Rev. 2 (2015), 041101. https://doi.org/10.1063/1.4935926. 